\title{
Erratum to: The role of BRAF mutation in patients with high-risk malignant melanoma treated with high-dose adjuvant interferon therapy
}

Tulay Akman • Ilhan Oztop • Yasemin Baskin • Mahdi Akbarpour • Olcun Umit Unal •

Utku Oflazoglu • Hulya Ellidokuz • Banu Lebe

Published online: 10 February 2015

(c) Springer Science+Business Media New York 2015

Erratum to: Med Oncol (2015) 32:440

DOI 10.1007/s12032-014-0440-7

Unfortunately, Dr. Banu Lebe was not included as one of the authors in the original publication of the article. The correct order of authors and Dr. Banu Lebe's affiliation are provided in this erratum.

The online version of the original article can be found under doi:10.1007/s12032-014-0440-7.

T. Akman $(\bowtie)$

Department of Medical Oncology, Tepecik Training and Research Hospital, Gaziler Caddesi, No: 468 Yenisehir, Izmir, Turkey

e-mail: tulaytuzel@gmail.com

I. Oztop · U. Oflazoglu

Department of Medical Oncology, Dokuz Eylul University

Faculty of Medicine, Izmir, Turkey

Y. Baskin · M. Akbarpour

Department of Basic Oncology, Institute of Oncology,

Dokuz Eylul University, Izmir, Turkey

O. U. Unal

Department of Medical Oncology, Ataturk University, Erzurum, Turkey

H. Ellidokuz

Department of Preventive Oncology, Institute of Oncology,

Dokuz Eylul University, Izmir, Turkey

B. Lebe

Department of Pathology, Dokuz Eylul University

Faculty of Medicine, Izmir, Turkey 